Session 3232

\title{
The Effect of Study Journals on Student Performance and Attitudes in an Electrical Engineering Course
}

\author{
Cameron H. G. Wright, Donna E. Peterson, Parris C. Neal \\ Department of Electrical Engineering \\ U.S. Air Force Academy, CO \\ Cindy L. Lynch \\ Independent Scholar \\ New Concord, KY
}

\begin{abstract}
One hundred and eighty nine students enrolled in a sophomore electrical engineering circuits class were asked to keep a journal of their study habits, observations, and attitudes regarding the course as it progressed through the semester. They were periodically asked to turn in parts of their journal for review, with a submittal of a two-page study journal summary at midterm and the end of the semester. This paper describes how the use of a study journal in this way improved many students' awareness of their study habits for the course and enhanced their overall educational experience. Data are presented in the form of student comments excerpted from their study journal summaries. The authors discuss inferred improvements in the students' cognitive development. While difficult to prove, the authors postulate that the use of a study journal ultimately benefits the students' attitude and performance in follow-on engineering classes and can aid techniques such as problem-based learning.
\end{abstract}

\section{INTRODUCTION}

Early in their college careers, many engineering students have difficulty mastering their more technical classes, sometimes not realizing that these classes typically require a different approach to studying (i.e., reading coupled with the practice of problem sets) compared to other classes such as history or literature (where reading alone is the normal study mode). This can lead to early frustration with engineering and is a contributing factor to the high attrition rates experienced by all the engineering disciplines. ${ }^{1,2}$ Thus any method that improves our students' study habits may increase retention rates and potentially improve overall student performance.

For us, another motivation for improving our students' study habits results from one of the specific educational outcomes stipulated for the U.S. Air Force Academy (USAFA), which states we must produce "officers who can frame and resolve ill-defined problems." In this context, an ill-defined problem (sometimes referred to in the literature as an unstructured problem) is ambiguous, iterative, and ever-changing. This type of problem lacks certainties related to the validity and completeness of the data available, the range of solution options, and the outcomes that follow from various solutions. If experts might disagree about the best solution, it can be called an ill-defined problem. Obviously, ill-defined problems abound in engineering, and the desire to graduate students who can handle this type of problem is not unique to USAFA. While simply improving our students' study habits will not, by itself, result in the ability to frame and 
resolve ill-defined problems, it is a necessary component for achieving that educational outcome. Thus we seek a method that will facilitate improvements in student study habits, and from that raise the level of their academic performance and enhance their overall educational experience. It is the authors' opinion, furthermore, that increasingly popular problem-based learning (PBL) techniques would benefit greatly from this method. ${ }^{3}$

\section{BACKGROUND}

When we as professors seek to improve the learning process of our students, it is helpful to have some sort of model for cognitive development to which we can refer. There is no shortage of models in the literature from which to choose; Bloom, Dewey, Perry, and others have all proposed various models to describe the process of learning. ${ }^{4-7}$ Given our emphasis on developing our students' ability to frame and resolve ill-defined problems, the authors find the most suitable model for our efforts in this context to be the reflective judgment model of adult cognitive development. ${ }^{8-12}$ The skills required to frame and resolve ill-defined problems are imbedded in the reflective judgment model, which has been validated by over 20 years of crosssectional and longitudinal research. The USAFA Levels of Performance for Framing and Resolving Ill-Defined Problems ${ }^{13}$ (see Appendix) are based on the reflective judgment model and related research findings regarding typical performance of undergraduate students. Because the thrust of this paper is to describe the use of study journals rather than expound on the model, the reader is directed to the references for more detail regarding the reflective judgment model.

Asking students to maintain a study journal as described in the next section is an indirect way of asking them the question, "What is the best way to study for engineering courses?" Not by coincidence, that question represents an ill-defined problem. Thus by maintaining a study journal and pondering how best they might study for this engineering course, they are not only potentially improving their study habits (which is needed to progress toward cognitively complex reflective thinking required for ill-defined problems), but they are also getting exposure to and practice with an ill-defined problem. This helps us achieve in two ways our desired educational outcome of "officers who can frame and resolve ill-defined problems."

\section{METHOD}

The original idea of using study journals to improve student study habits for engineering courses came to the authors from a short article by Sweidel in The Teaching Professor. ${ }^{14}$ We decided to try the concept in a single electrical engineering (EE) class, EE 231, "Electrical Circuits and Systems I." This class provides an introduction to circuit analysis and system design, circuit models of electrical devices and systems, nodal and mesh analysis, Thevenin and Norton equivalent circuits, operational amplifier circuits, transient response of first-order circuits, sinusoidal steady-state response, analog-to-digital and digital-to-analog converters, and a systems-level overview of electronic communication systems. It is a sophomore-level class and constitutes the first EE class taken by our EE majors; it is also taken by students in some other technical disciplines at USAFA: astronautical engineering, mechanical engineering, engineering sciences, computer science, and physics. 
Over the period of two semesters, Spring 1996 and Fall 1996, all of the one hundred and eighty nine EE 231 students were asked to keep a journal of their study habits, observations, and attitudes regarding the course as it progressed through the semester. They were instructed to make journal entries 16 times at regularly spaced intervals throughout the semester and were asked to turn in a two page (double spaced) journal summary, as well as their entire journal for review, both at mid-semester and the end of the semester. The students were informed that this activity constituted 5\% of their midterm grade (important at USAFA because it helps determine cadet privileges) and a total of $4 \%$ of their final grade in the course. Specifically, the students were asked to answer to the following question in their journal summary:

What are your current study habits and how effective have they been in this course?

After reviewing the responses from the Spring 1996 class, the directions were made more specific. In addition to answering the above primary question, the students were to consider the following secondary questions:

1. What, if anything, have you learned about your study habits this semester?

2. Have you made any changes this semester in how you study, take tests, or think/feel about your school work?

-- If no, why not?

-- If yes, what changes have you made and why? With what results?

3. What do you think is the best way to study? What is the basis for your opinion?

4. Do you think it's possible to know for sure if your opinion about the best way to study is correct?

-- If yes, how do you know?

-- If no, why can't you know for sure?

5. When people disagree about how to study, does this mean that one opinion is correct and the others are wrong?

-- If yes, how do you decide which opinion is correct?

-- If no, is one opinion better than the others? How would you decide which opinion is best?

The secondary questions, particularly 3, 4, and 5, lead the students into the unfamiliar territory of the ill-defined problem. The questions were adapted from King and Kitchner's Reflective Judgment Interview. ${ }^{9}$ Having responses to these questions in an informal essay context allowed us to look at examples of students' reasoning about the ill-defined problem of developing effective study habits. The Levels of Performance in the Appendix would thus be used as one way to evaluate the essays. Other professors who may choose to implement a study journal project for their classes will find that fine-tuning of the student instructions, such as we indicate above, will be necessary to achieve the desired results as the project evolves.

\section{RESULTS}

As with all unfamiliar activities, most students were resistant at first to the idea of keeping a study journal; some complained rather eloquently. The better students were more adamant than others, using a typical argument of "I get good grades already so I must know how to study!" Some argued that it was an EE class and the study journal was not an EE activity. The professors 
patiently explained to all that the exercise was for the students' benefit and would not be rescinded.

By the end of the semester, positive remarks about the study journal exercise were nearly universal among the students. Almost all students indicated that the time and energy devoted to the study journal helped them learn how to study better. Even the better students, who complained the loudest in the beginning, were amazed that they learned to study even more efficiently than before. Poorer students gained insight into study activities that were not as productive as they had hoped. Some students commented that they applied what they learned from the EE 231 study journal to other classes with very positive results. For us, one of the most encouraging types of comments found in the end of semester summaries were similar to "The study journal helped me stop worrying about the grade I'll get and concentrate more on how I study the course material, and as a result I received a better grade."

Some direct quotes from student summaries, each from a different student, are given below. The final grades of these students ranged from A to D, and are given in no particular order.

- "When I found out I had to keep a study journal, I was definitely not overjoyed. However, after keeping a journal all semester, I realized that it taught me a lot about my study skills and class preparation."

- "After reviewing my journal, it was apparent that there was a trend in my study habits and grades. When I did the homework and went in for extra instruction, there was a dramatic improvement in my grades. I got into a bad cycle of doing well and then letting up."

- "By looking at the study journal I had written for the first [exam], I was able to make changes to my study plans... These techniques have helped me become a better student. I was able to get better grades on [exams] not only in this class, but also in all my other classes as well."

- "I felt I have improved my study skills, not only in this class, but in all of my classes."

- "What I learned for study habits is that because I had to write in a study journal I thought about what I actually did to study, and that made me aware as to what I did that helped me do well. The one thing I changed was that I studied with a group before [exam 2] and I think that helped me so I also studied with a group for [exam 3]. I got 93 and 100, respectively, which shows that the change had positive results."

- "After reviewing my journal entries, I have noticed a general pattern or trend which is occurring in both EE and my other classes. The improvements that I have made have been for the better, and I should continue to work on improving them in the future."

- "Throughout the semester I have learned a great deal about my personal study habits and skills. From this knowledge of my habits, I have been able to improve and develop my skills and habits immensely. I feel this semester has helped me greatly with my personal study techniques."

- "The study journal I have kept for EE 231 has helped me improve my performance, especially in the area of studying, throughout the semester. As a result of filling in and updating my journal after certain lessons and [exams], I have been able to reflect upon my performance in this course more often than in other courses I have taken. Each time I reviewed my accomplishments, I saw certain weaknesses that I was able to correct. I feel I 
have changed some of my study habits (not only in this class) this semester as a result of the journal I have kept."

- "I think a study journal can be beneficial for individuals who have not quite found the groove in college school work. It helps them explore their approach to studying from new angles, and maybe re-evaluate their methods."

- "I think that my study skills are serving me well. One thing that I have noticed however is that I sometimes spend far too much time trying to redo problems that I don't get on the first try (before class). I decided to give those problems a rest until after the lecture, and then they were easy! After I made this change, I noticed that the amount of time I spent erasing my papers went down considerably and I was able to get more done in my other classes!"

- "I have made some observations this semester on how to study better. A lot of this came through studying for EE. I didn't like EE231; rather, it was one of my hardest classes, and one I liked the least. It did teach me a lot, though, and I even learned something about myself. It was a fun class and I learned a lot."

- "I had never really spent any time analyzing [my study habits], so I just let whatever happened happen, and I went on my merry way. But now that I have spent some time analyzing them, I'm realizing that I am extremely lazy."

- "My experience with EE231 essentially taught me that my old study habits were ineffective. ...Of course, old habits are hard to break. ...After [exam 2], I made a change in my study habits. Rather than memorize how to do specific problems, I learned the concepts and more general approaches to solving EE problems. As a result I spent less time studying and received a higher score on my exam. I think I have learned how to study more effectively and efficiently."

- "I did not change my study habits this semester. I did however change the way I did the tests."

- "This journal actually is helpful for identifying what I need to do and how I should be budgeting my time."

- "Even though I was not thrilled with the idea of study journals early on in the semester, I think it has been a beneficial tool and has helped me reflect on what helps me to do the best I can."

- "In this course I have developed new ways to accomplish homework, but more importantly new ways of learning which improve a lot of things including test taking skills."

- "At the beginning of the class I thought this was a stupid idea but it has turned out to be fairly helpful."

- "When it came time to review my study journal for the first half of the semester and reflect on my study habits I found my studying was inconsistent. ... Fortunately, I took my advice on how to improve my study habits. For the second half of the semester I have spent much less time studying, but I have maintained the amount I have learned, and even improved my exam scores by an average of 10 points per exam." 
As discussed earlier in this paper, the study journal exercise in itself constitutes an ill-defined problem. When the students' summary essays were evaluated in terms of the Levels of Performance (see Appendix), statements from students indicated a wide range of ability to frame and resolve such a problem. Some students evidenced improvement in handling the ill-defined problem of study skills between the mid-semester and end of semester comments in the journal summaries, but the sample size is still too small to draw any definitive conclusions. We anticipate that the study journal exercise, as one tool in a large array of techniques, will help bring us closer to attaining our desired educational outcome of "officers who can frame and resolve ill-defined problems." We plan further analysis of the data and will also obtain more data as the exercise is continued through future semesters.

One disadvantage of assigning students to keep study journals needs to be elucidated. We are keenly aware, as are most professors, of practical limits to the time required of students inside and outside of class that must be devoted to each course. The cadets at USAFA, in particular, have extremely heavy time commitments due to their academic, military, and athletic responsibilities. The authors thus consciously chose not to increase the overall time requirements of the EE 231 class, even though the study journal was a new requirement. As a result, a small amount of subject content was removed from the course to compensate for the time required of the students to maintain and summarize the study journals. In light of the apparent advantage of the study journals, the authors are satisfied with this trade-off.

\section{CONCLUSIONS}

The study journal exercise described herein proved to be an effective method to improve students' awareness of their study habits and enhance their overall educational experience. While it is too early to have definitive quantifiable data as support, the authors postulate that the use of a study journal ultimately will benefit the students' attitude and performance in subsequent classes. We further believe that the exercise facilitates cognitive development toward the higher levels of reflective thinking required for ill-defined problems and can also work synergistically with the increasingly popular problem-based learning techniques.

While we address above the initial reluctance of students to maintain study journals, we recognize the equally likely reluctance of faculty members to invest the time and effort into such an activity. Given the extremely positive initial results we have seen, the authors highly recommend that study journals be given serious consideration as a tool that can benefit the cognitive development of their students.

\section{ACKNOWLEDGMENT}

The authors appreciate the support of The Center for Educational Excellence at the U.S. Air Force Academy. 


\section{REFERENCES}

[1] LeBold, W.K., and Ward, S.K., "Engineering Retention: National and Institutional Perspectives," Proceedings of the 1988 ASEE Annual Conference, pp. 843-851. Jun. 1988.

[2] Morrow, R.M., "Issues Facing Engineering Education," ASEE Journal of Engineering Education, vol. 83, no. 1, pp. 15-18, Jan. 1994.

[3] Hendley, V., et al., "Let Problems Drive the Learning,” ASEE Prism, pp. 30-36, Oct. 1996.

[4] Bloom, B.S., ed., Taxonomy of Educational Objectives: The Classification of Educational Goals, Handbook I: Cognitive Domain, David McKay, 1956.

[5] Dewey, J., How We Think: A Restatement of the Relation of Reflective Thinking to the Educative Process, D.C. Heath and Co., 1933.

[6] Perry, W.G., Jr., Forms of Intellectual and Ethical Development in the College Years: A Scheme, Holt, Rinehart \& Winston, 1970.

[7] Pavelich, M.J. and Moore, W.S., "Measuring the Effect of Experiential Education Using the Perry Model," ASEE Journal of Engineering Education, vol. 85, no. 4, pp. 287-292, Oct. 1996.

[8] King, P.M., ed., Liberal Education, vol. 78, no. 1, Jan/Feb 1992, Special issue on reflective judgment.

[9] King, P.M. and Kitchner, K.S., Developing Reflective Judgment: Understanding and Promoting Intellectual Growth and Critical Thinking and Adolescents and Adults, Jossey-Bass, 1994.

[10] Kitchner, K.S. and King, P.M., "Reflective Judgment: Concepts of Justification and Their Relationship to Age and Education," Journal of Applied Developmental Psychology, vol. 2, pp. 89-116, 1981.

[11] Lynch, C.L., "Facilitating and Assessing Unstructured Problem Solving," Journal of College Reading and Learning, vol. 27, no. 2, pp 16-27, Fall 1996.

[12] Schon, D.A., Educating the Reflective Practitioner: Toward a New Design for Teaching and Learning in the Professions, Jossey-Bass, 1991.

[13] Lynch, C.L., Kitchner, K.S. and King, P.M., Developing Reflective Judgment in the Classroom: A Manual for Faculty in the Department of Behavioral Sciences and Leadership at the United States Air Force Academy, Reflective Judgment Associates, 1995.

[14] Sweidel, G.B., "Study Strategy Portfolio," The Teaching Professor, p. 2, Nov. 1995.

Major CAMERON H. G. WRIGHT, PhD, PE, is an Assistant Professor in the Department of Electrical Engineering at the U.S. Air Force Academy. His research interests include signal and image processing, biomedical instrumentation, communications systems, and laser/electro-optics applications. He is a member of ASEE, IEEE (Senior Member), SPIE, Tau Beta Pi, and Eta Kappa Nu. Email: cwright@tesla.usafa.af.mil

Lieutenant Colonel DONNA E. PETERSON, PhD, is an Assistant Professor in the Department of Electrical Engineering at the U.S. Air Force Academy. Her research interests include musical acoustics and teaching introductory electronics. She is a member of ASEE and IEEE. Email: petersonde.dfee@usafa.af.mil

Colonel PARRIS C. NEAL, PhD, is Senior Military Professor in the Department of Electrical Engineering at the U.S. Air Force Academy. His research interests include instrumentation, computer architecture, acoustics, and audio electronics. He is a member of ASEE, IEEE, Tau Beta Pi, and Phi Kappa Phi. Email: nealpc.dfee@usafa.af.mil

CINDY L. LYNCH, PhD, is an independent scholar and consultant with extensive experience with the reflective judgment model. She has consulted for a variety of organizations including the U.S. Air Force Academy, and may be contacted at 286 Lake Shore Drive, New Concord, KY 42076, via telephone at (502) 436-5839, or via email at: 74671.2342@compuserve.com 


\section{APPENDIX}

\section{USAFA Levels of Performance for Framing and Resolving Ill - Defined Problems}

A working group of USAFA faculty led by Colonel David Porter, $\mathrm{PhD}$ addressed assessment issues related to the Academy's stated educational outcomes. This faculty group consulted with Dr. Cindy L. Lynch about the reflective judgment model of adult cognitive development. As a result, the following USAFA Levels of Performance (LOPs) are based, in part, on the reflective judgment model. As you read through these statements, think about the differences in cognitive complexity portrayed in the Excellent, Satisfactory, and Deficient categories.

\section{EXCELLENT}

- identifies most important ill-defined aspects of problem as well as general "ill-defined" problem nature

- keenly aware of personal perspective and biases, and compensates effectively

- also aware of relationship between present problem and context in which it is situated

- uses goal, mission, or other ultimates to structure problem space effectively

- systematically works through problem; often makes multiple passes through the problem space as conditions change in order to assess consequences of changes or alternatives

- unsuccessful attempts regularly used to better understand problem and solution process

- generated rich variety of alternatives; test them objectively and selects rationally

- uses general principles and fundamental concepts to frame overall problem space and as solutions tools; provides reasonable and substantive justification for assumptions and choices

- appropriate level of confidence and commitment to eventual solution

\section{SATISFACTORY}

- aware of general ill-defined nature of the problem and some of the specific problem deficiencies

- somewhat aware of personal perspective, but not fully able to compensate for its effects

- evidence of awareness of problem context found throughout solution process, but some important connections and implications not recognized

- may structure problem space based superficial problem characteristics or unwarranted assumptions

- works through problem systematically, but may omit necessary reconsideration of assumptions

- unsuccessful attempts recognized and abandoned

- generates multiple potential solutions, but may not consider them all or use appropriate selection criteria

- tendency to use particular tools and mechanisms appropriately, but may lack ability to justify the approach taken or adjust tools to fit the problem presented

- likely to lack confidence in solution; limited commitment without encouragement or support

\section{DEFICIENT}

- unaware of either general or specific characteristics that preclude routine solution procedures 
- apparently unaware of personal perspectives, biases, or assumptions and their effects

- apparently unaware of broader context in which problem occurs; assumes singular perspective

- unable or unwilling to structure the problem space within parameters provided

- unsuccessful, sporadic, apparently random attempts at problem lead to frustration and abandonment

- unsuccessful attempts based on untenable assumptions not recognized

- fully commits to first apparent solution path and follows it through to completion without reconsideration

- random or inappropriate application of tools; may not be able to provide reasons for approach selected

- likely to display either no confidence in solution or process (may claim problem is impossible) or be inappropriately confident and overly committed to obviously ineffective solution 